\title{
Prevalence of Adhesion and Regulation of Biofilm-Related Genes in Different Clones of Staphylococcus aureus
}

\author{
Salman Sahab Atshan,, ${ }^{1,2}$ Mariana Nor Shamsudin, ${ }^{1,3}$ Zamberi Sekawi,1 \\ Leslie Than Thian Lung, ${ }^{1}$ Rukman Awang Hamat, ${ }^{1}$ Arunkumar Karunanidhi, ${ }^{1}$ \\ Alreshidi Mateg Ali, ${ }^{1}$ Ehsanollah Ghaznavi-Rad, ${ }^{4}$ Hamed Ghasemzadeh-Moghaddam, ${ }^{1}$ \\ Johnson Shueh Chong Seng, ${ }^{1}$ Jayakayatri Jeevajothi Nathan, ${ }^{1}$ and Chong Pei Pei ${ }^{5}$ \\ ${ }^{1}$ Laboratory of Medical Microbiology and Parasitology, Faculty of Medicine and Health Science, Universiti Putra Malaysia, \\ Selangor 43400 Serdang, Malaysia \\ ${ }^{2}$ Department of Medical Microbiology, Basrah University, Basrah, Iraq \\ ${ }^{3}$ Laboratory of Marine Science and Aquaculture, Institute of Bioscience, Universiti Putra Malaysia, Selangor 43400 Serdang, Malaysia \\ ${ }^{4}$ Department of Microbiology and Immunology, Arak University of Medical Sciences, Arak, Iran \\ ${ }^{5}$ Department of Obstetrics and Gynaecology, Faculty of Medicine and Health Science, Universiti Putra Malaysia, Putra Malaysia, \\ Selangor 43400 Serdang, Malaysia
}

Correspondence should be addressed to Salman Sahab Atshan, salmanatshan@yahoo.com

Received 25 February 2012; Revised 10 March 2012; Accepted 4 April 2012

Academic Editor: Daniele Daffonchio

Copyright ( 2012 Salman Sahab Atshan et al. This is an open access article distributed under the Creative Commons Attribution License, which permits unrestricted use, distribution, and reproduction in any medium, provided the original work is properly cited.

\begin{abstract}
Clinical information about genotypically different clones of biofilm-producing Staphylococcus aureus is largely unknown. We examined whether different clones of methicillin-sensitive and methicillin-resistant S. aureus (MSSA and MRSA) differ with respect to staphylococcal microbial surface components recognizing adhesive matrix molecules (MSCRAMMs) in biofilm formation. The study used 60 different types of spa and determined the phenotypes, the prevalence of the 13 MSCRAMM, and biofilm genes for each clone. The current investigation was carried out using a modified Congo red agar (MCRA), a microtiter plate assay (MPA), polymerase chain reaction (PCR), and reverse transcriptase polymerase chain reaction (RT-PCR). Clones belonging to the same spa type were found to have similar properties in adheringto the polystyrene microtiter plate surface. However, their ability to produce slime on MCRA medium was different. PCR experiments showed that 60 clones of MSSA and MRSA were positive for 5 genes (out of 9 MSCRAMM genes). icaADBC genes were found to be present in all the 60 clones tested indicating a high prevalence, and these genes were equally distributed among the clones associated with MSSA and those with MRSA. The prevalence of other MSCRAMM genes among MSSA and MRSA clones was found to be variable. MRSA and MSSA gene expression (MSCRAMM and $i c a A D B C$ ) was confirmed by RT-PCR.
\end{abstract}

\section{Introduction}

Biofilms are structured community of bacterial cells enclosed in a self-produced polymeric matrix and are capable of adhering to an inert or living surface [1]. Although biofilm forming properties have been well demonstrated in members of Staphylococcus, such as S. epidermidis and S. aureus, still they remain unclear among the recently emerged types of methicillin-resistant Staphylococcus aureus (MRSA), which have evolved from several clonal lineages of methicillin susceptible S. aureus (MSSA) strains. Researchers showed that the first step of staphylococcal infection is the attachment to surfaces of various materials, including medical devices and host tissues. These reactions are attributed to a combination of extracellular factors such as adherence and biofilm formation [2]. S. aureus can express a variety of microbial surface components recognizing adhesive matrix molecules (MSCRAMMs) that interact with host extracellular ligands, such as elastin binding protein $(e b p S)$, laminin binding protein (eno), collagen binding protein (cna), fibronectin binding proteins $\mathrm{A}$ and $\mathrm{B}(\mathrm{finb}$ A, finbB), fibrinogen binding protein $(f i b)$, clumping factors $\mathrm{A}$ and $\mathrm{B}(\operatorname{clf} A, \operatorname{clf} B)$, and bone 
sialoprotein binding protein $(b b p)$. Molecular studies have shown that during late phases of adherence the organisms first adhere to each other and then elaborate a biofilm. This step is mediated by two biofilm components, polysaccharide intercellular adhesion (PIA) and the intracellular adhesion $\mathrm{A}, \mathrm{D}, \mathrm{B}$, and $\mathrm{C}(i c a A, i c a D$, icaB, and $i c a C)$, which are synthesized by products of the intercellular adhesion $\mathrm{A}$, $\mathrm{D}, \mathrm{B}$, and $\mathrm{C}$ (icaA, icaD, icaB, and icaC) operon. These operon genes encoding the proteins are necessary for the synthesis of polysaccharide intercellular adhesion (PIA) and capsular polysaccharide/adhesion (PS/A), which remain as the major biofilm components in staphylococcal species [3]. The involvement of biofilms in clinical infections has received increasing interest due to the characterization of genes involved in biofilm formation $[4,5]$. Therefore, the different clones isolated from different clinical sources can make a difference in the adhesion and/or ability to form biofilm. In this study, we investigated the biofilm risk factors and diagnostic marker for the production of biofilm related to genotypic and phenotypic characterizations of MSSA and MRSA clones. Evaluation of gene expression within these two diverse groups by RT-PCR would be more advantageous in determining their relation.

\section{Materials and Methods}

2.1. Bacterial Strains. In total, stock cultures of 60 different clinical MSSA and MRSA were collected from the Medical Microbiology Laboratory at the Universiti Putra Malaysia. All the isolates were confirmed from a previous epidemiology study conducted by Ghaznavi-Rad et al. and GhasemzadehMoghaddam et al. [11, 12]. The source of the isolates was from different systemic infection sites of clinically ill patients of Kuala Lumpur General Hospital. The isolates were characterised as different clones using Staphylococcal Cassette Chromosome mec (SCCmec) typing, Staphylococcal surface protein A (spa) typing, and multilocus sequence typing (MLST). Slime-producing S. aureus ATCC 35556 [13] and non-slime-producing S. epidermidis ATCC12228 [14] were the two reference strains used in this study.

2.2. Slime Assay. Slime-producing clones of MRSA and MSSA were identified using Congo red agar (CRA) following the method as described by Mariana et al. [15]. The clones were incubated at $37^{\circ} \mathrm{C}$ for $48 \mathrm{~h}$ under aerobic conditions. The experiment was performed in triplicates, and the colonies formed over CRA medium were categorized as very black, black, and weak black. The black colonies were considered to be normal slime-producing strains whereas red colonies were classified as non-slime-producing strains [16].

2.3. Adherence Assay. To study the adherence phase, a modified microtiter plate method was followed as previously described by Stepanović et al. [17]. Briefly, all the MSSA and MRSA clones were grown in trypticase soy broth (TSB) containing $1 \%$ glucose (Baker, UK) in 6-well polystyrene tissue culture plates (Roskilde, Denmark) and incubated at $37^{\circ} \mathrm{C}$ for $48 \mathrm{~h}$ under aerobic conditions. After incubation, the planktonic cells were washed ten times with deionised water, and the adhering bacterial cells in each well were fixed with $2 \mathrm{~mL}$ of absolute methanol for 20 mins. The plates were emptied and left to dry overnight. The adhering cells were stained with $1 \mathrm{~mL}$ of $0.1 \%$ safranin for $15 \mathrm{~min}$, and excess stain was rinsed off. The plates were washed thrice with distilled water and air-dried overnight. The safranin dye bound to the adherent cells was dissolved with $1 \mathrm{~mL}$ of $95 \%$ ethanol per well, and the plates were read at $490 \mathrm{~nm}\left(A_{490}\right)$ using a spectrophotometer (Eppendorf AG, 2233, Hamburg, Germany). The experiment was performed in triplicates, and the absorbance $\left(A_{490}\right)$ of wells containing sterile TSB was used as the negative control. An $A_{490}$ value of 0.5 was taken as the cutoff point to differentiate between the clones for adhesion quantities (optical density cutoff $(\mathrm{ODc})=$ average OD of negative control $+3 \times$ standard deviation (SD) of negative control). Formation of adhesion by strains was analyzed and categorized based on the absorbance of the safranin-stained attached cells. Clones were considered as highly adherent $++++\left(A_{490}>3.0\right)$, strongly adherent +++ $\left(3.0>A_{490}>2.0\right)$, moderately adherent $++\left(2>A_{490}>1\right)$, weakly adherent $+\left(1>A_{490}>0.5\right)$, and negatively adherent - $\left(A_{490}<0.5\right)$ on the basis of their absorbance property.

2.4. Polymerase Chain Reaction (PCR). The purpose of using simplex and multiplex PCR was to determine the distribution of 13 MSCRAMMs and biofilm genes in 60 genotypically different clones of $S$. aureus isolates. Total chromosomal DNA was extracted from the isolates using a DNeasy kit (Qiagen Inc.) according to the manufacturer instructions. No reference strains were available for the MSCRAMM genes ( $b b p, c l f A, c l f B, c n a, e b p S$, eno, $f n b A, f n b B$, and $f i b$ ), and all the 9 genes were amplified by simplex PCR. The distribution of 13 MSCRAMM and biofilm genes in different clones of $S$. aureus isolates was examined by multiplex PCR method. All primer sets for adhesion and biofilm genes were previously described by Rohde et al. [6], Kiem et al. [7], Vancraeynest et al. [9], Cucarella et al. [4], Montanaro et al. [10], and Tristan et al. [8] as shown in Table 1 and were synthesized by BioRP. The primers were analyzed for their specificities using the endpoint PCR product in 1.4\% agarose gel electrophoresis as well as the melting curves. The identities of PCR products were further confirmed by sequencing. The amplicons of clones that are found to be positive for most of the selected genes by PCR assays were subjected to DNA sequencing for the confirmation of gene specificities (MRSA-spa t037 and MSSA-spa t14413). The reaction mixture of PCR was $25 \mu \mathrm{L}$ in total volume containing $12.5 \mu \mathrm{L}$ of master mix, $1.0 \mu \mathrm{L}$ of primers (forward $0.5 \mu \mathrm{L}$ and reverse $0.5 \mu \mathrm{L}$ ), $2 \mu \mathrm{L}$ of genomic DNA, and $9.5 \mu \mathrm{L}$ of distilled water $\left(\mathrm{dH}_{2} \mathrm{O}\right)$. PCR was carried out with an initial denaturation step of $10 \mathrm{~min}$ at $95^{\circ} \mathrm{C}$, followed by 25 cycles of denaturation ( $1 \mathrm{~min}$ at $\left.94^{\circ} \mathrm{C}\right)$, annealing $\left(1 \mathrm{~min}\right.$ at $\left.55^{\circ} \mathrm{C}\right)$, and extension $(1 \mathrm{~min}$ at $72^{\circ} \mathrm{C}$ ); the reactions were finalized by polymerization for $10 \mathrm{~min}$ at $72^{\circ} \mathrm{C}$. Multiplex PCR was carried out using the Qiagen Multiplex PCR kit (Qiagen) following the method as described by Ghaznavi-Rad et al. [11] with slight modifications in PCR thermal cycler program. Briefly, 


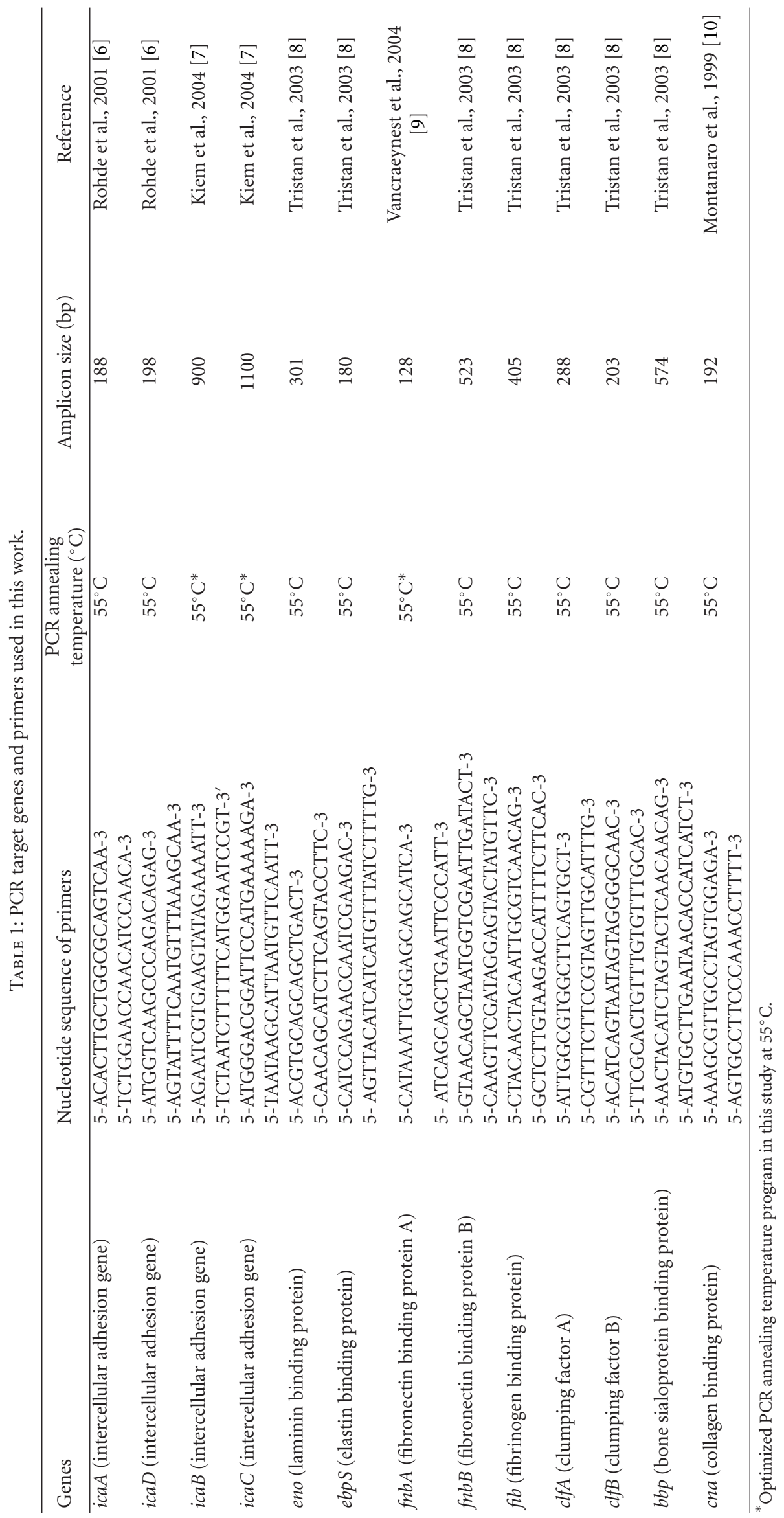




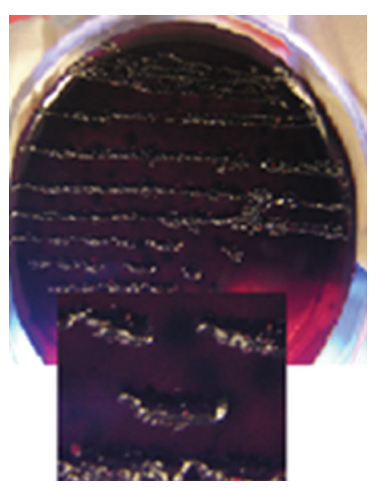

Very black colonies

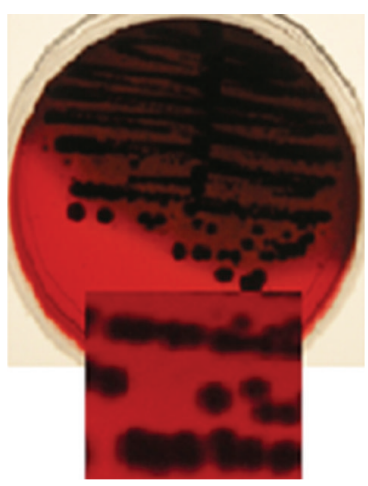

Black colonies

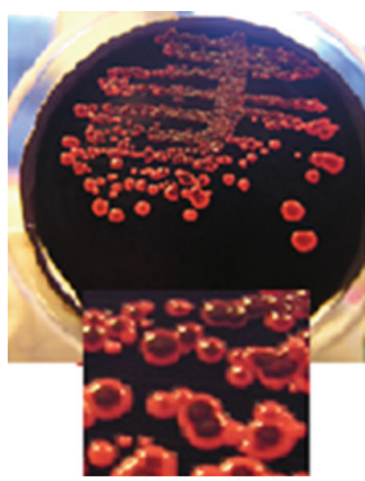

Weak black colonies

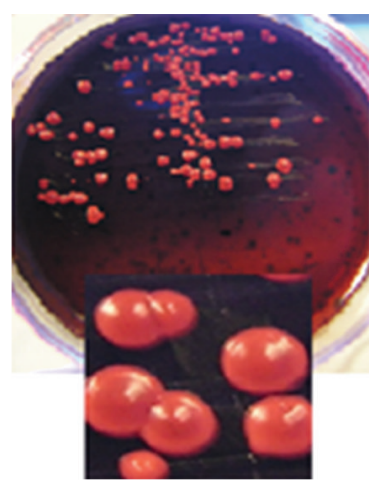

Red colonies

FIgURE 1: Colony morphologies of clinical S. aureus isolates on the modified Congo red agar medium.

reaction mixtures containing $1 \mu \mathrm{g}$ chromosomal DNA, $25 \mu \mathrm{L}$ of master mix with $3 \mathrm{mMMgCl}_{2}, 5 \mu \mathrm{L}$ of primer mix $(2 \mu \mathrm{M}$ in TE buffer for each primer), and RNase-free water in a final volume of $50 \mu \mathrm{L}$ was prepared. The reaction was carried out in the Biometra T PCR system (Biometra-Gottingen, Germany) using the same PCR thermocycler program as earlier mentioned above. The PCR amplicons were visualized using UV light (Alpha Imager) after electrophoresis in a $1.4 \%(\mathrm{w} / \mathrm{v})$ agarose gel containing $0.01 \mu \mathrm{L}$ GelRed $\mathrm{mL}^{-1}$ (Biotium).

2.5. Reverse Transcriptase Polymerase Chain Reaction (RTPCR) Method. Semiquantitative RT-PCR-based protocols for the specific genes encoding adhesions in genotypically different clones of $S$. aureus performed biofilms were carried out by following the method described elsewhere [18]. The results obtained were compared with the morphological traits of the different clones tested. For RNA isolation, suspensions of spa types were grown in 6-well polystyrene tissue culture plates supplemented with trypticase soy broth (TSB) containing $1 \%$ glucose and incubated at $37^{\circ} \mathrm{C}$ for $48 \mathrm{~h}$ under aerobic conditions. After incubation, the plates were washed with deionized water to remove the planktonic cells. Immediately, the wells containing attached cells were treated with an appropriate volume of RNAprotect (QIAGEN), vortexed for 5 seconds, and incubated for $5 \mathrm{~min}$ at room temperature. The contents were centrifuged at $10,000 \times \mathrm{g}$ for $10 \mathrm{~min}$, and the supernatant was discarded. The pellet was resuspended in $100 \mu \mathrm{L}$ of RNase-free distilled water (Qiagen), and the cell densities were adjusted to comparable values and RNA isolation was performed as described elsewhere [19]. The quality and quantity of the isolated RNA was determined by agarose gel electrophoresis and confirmed by measuring the absorbance at $260 \mathrm{~nm}$ using a Nanodrop spectrophotometer ND-1000 (Thermo Fisher Scientific, Wilmington, DE, USA). Contaminating DNA in the RNA preparations was removed using "RNase-free DNase I and gDNA wipeout buffer" (Qiagen). Purified RNA samples were converted to cDNA according to the manufacturers instructions (QuantiTect Reverse Transcription kit, Qiagen), and the CDNA was directly used as template for RT-PCR following the same PCR conditions mentioned earlier. A total of 25 PCR cycles were run, and the RT-PCR products were examined by agarose gel electrophoresis and Nanodrop spectrophotometer. The gene expression was compared with 6 different clones of spa types, which included weakly adherent 3 clones (positive for 12 genes except $f n b B$ ) and strongly adherent 3 clones (positive for 12 genes except $b b p$ gene). Selected RT-PCR amplicons were quantified using a Nanodrop spectrophotometer, and the experiment was performed in duplicates.

2.6. Statistic Analysis. Statistical analyses were made with one-way ANOVA. Categorical variables between more than two groups were tested, and $P$ values of $\leq 0.05$ indicated statistical significance.

\section{Results}

3.1. Slime Production on Modified Congo Red Agar (MCRA). The numbers of different slime-producing clones of MSSA and MRSA on modified Congo red agar were found to be different with varying degrees like very black, black, weak black, and red colonies (Table 2 and Figure 1). There were no negative reactions for the MSSA slime-producing clones tested, whereas 2 non-slime-producing MRSA clones were observed. Slime-producing S. aureus ATCC 35556 strain produced typical black colonies, and the non-slimeproducing strain S. epidermidis ATCC 12228 produced pink colonies on MCRA medium after $48 \mathrm{~h}$ of incubation.

3.2. Microtiter Tissue Culture Plates. All the MSSA and MRSA clones tested were found to be adherent at varying levels (Table 2). Adherence abilities of MSSA clones were found to be slightly higher than those of MRSA clones. Among the MSSA clones, $20 \%$ of the clones were highly strong, $46.6 \%$ were strong, $33.3 \%$ were moderate, and none of them were found to be nonadherent, whereas among the MRSA clones, $30 \%$ of the clones were found to be highly strong, $36.6 \%$ were strong, $26.6 \%$ were moderate, and $6.6 \%$ were found weakly adherent. Slime-producing S. aureus ATCC 35556 strain were found to be strongly adherent with an $\mathrm{OD}_{490 \mathrm{~nm}}(P$ value $>2.0)$, while the slime-producing 
TABLE 2: Slime production and adhesion formation by microtiter tissue culture plate and modified Congo red agar method.

\begin{tabular}{|c|c|c|c|c|c|}
\hline Method & Slime/adhesion formation & $\operatorname{MSSA}(n=30)$ & Percentage $(\%)$ & $\operatorname{MRSA}(n=30)$ & Percentage $(\%)$ \\
\hline \multirow{4}{*}{$\begin{array}{l}\text { Modified Congo } \\
\text { red agar }\end{array}$} & Very black & 8 & 26.6 & 7 & 23.3 \\
\hline & Black & 19 & 63.3 & 20 & 66.6 \\
\hline & Weak black & 3 & 10 & 1 & 3.3 \\
\hline & Red & 0 & 0 & 2 & 6.6 \\
\hline \multirow{5}{*}{$\begin{array}{l}\text { Microtiter tissue } \\
\text { culture plate }\end{array}$} & Highly & 6 & 20 & 9 & 30 \\
\hline & Strong & 14 & 46.6 & 11 & 36.6 \\
\hline & Moderate & 10 & 33.3 & 8 & 26.6 \\
\hline & Weak & 0 & 0 & 2 & 6.6 \\
\hline & None & 0 & 0 & 0 & 0 \\
\hline
\end{tabular}

TABLE 3: MSCRAMM and biofilm gene expression levels of 60 MRSA and MSSA clinical isolates tested.

\begin{tabular}{lcc}
\hline \multirow{2}{*}{ Gene } & $\begin{array}{c}\text { no\% genes expressed by RT-PCR* } \\
\text { MSSA }\end{array}$ & MRSA \\
\hline$i c a A$ & $30(100)$ & $30(100)$ \\
$i c a D$ & $30(100)$ & $30(100)$ \\
$i c a B$ & $30(100)$ & $30(100)$ \\
$i c a C$ & $30(100)$ & $30(100)$ \\
$f n b A$ & $30(100)$ & $30(100)$ \\
$f n b B$ & $9(100)$ & $16(100)$ \\
Fib & $27(100)$ & $27(100)$ \\
cna & $14(100)$ & $28(100)$ \\
eno & $30(100)$ & $30(100)$ \\
ebps & $30(100)$ & $30(100)$ \\
bbp & $4(100)$ & $3(100)$ \\
clfA & $30(100)$ & $30(100)$ \\
clfB & $30(100)$ & $30(100)$ \\
\hline
\end{tabular}

${ }^{*}$ Number (\%) of the MSCRAMM and biofilm gene expressions according to the presence of genes that were amplified by PCR.

S. epidermidis ATCC 12228 strains were found to be nonadherant with an $\mathrm{OD}_{490 \mathrm{~nm}}(P$ value $<0.5)$.

3.3. PCR Assay. All the primers used in the experiment showed specificity with a single band and a single peak (data not shown). The 9 MSCRAMM and 4 biofilm related genes were detectable in the MSSA and MRSA isolates by PCR method. As shown in Figure 2, the $f n b A$, eno, ebpS, clfA, $c l f B$, icaA, icaD, icaB, and icaC genes were detected (100\%) in both MSSA and MRSA clones. However, $b b p$ gene was detected only in 3 clones of MRSA that belonged to the same genetic background of spa, MLST, and SCCmec types (t091ST-7-CC7-V) isolated from different clinical sites), whereas $b b p$ gene was detected in 4 clones of MSSA that belonged to the same genetic background of MLST with different spa types ( $\mathrm{t} 159, \mathrm{t} 14413, \mathrm{t} 3204$, and $\mathrm{t} 4085)$. The prevalence of the other MSCRAMM genes among the MSSA clones was as follows: $f i b$ positive: $90 \%$, cna positive: $46.6 \%$, and $f n b B: 30 \%$. whereas, the prevalence of $f i b, c a n$, and $f n b B$ in MRSA clones was 90\%, 93\%, and 53.33\% respectively.
The MSCRAMM and biofilm genes were found to be highly predominant in 21 clones of 60 MRSA and MSSA clinical isolates, 16 clones were positive for 12 of the 13 genes, with the exception of $b b p$, while the remaining 5 clones were found to be $b b p$ positive and $f n b B$ negative. The selected 21 clones of $S$. aureus (highly predominant) were used in multiplexPCR experiment. The reaction was set in order to amplify 10 genes (5 MSSA clones and 16 MRSA clones) in one reaction, and the amplified PCR products from each reaction was shown in Figures 3(a) and 3(b). The PCR product amplicons of the remaining 3 genes (icaA, icaD, and cna) were found to be converging, therefore they were amplified by simplex-PCR (data not shown). From our observation, these clones harboured most of the MSCRAMM and biofilm genes and can be used as positive references for bacterial biofilm researchers. DNA sequences of target PCR products of the two clones studied were found to have 95-99\% identity corresponding to GenBank sequences (data not shown).

3.4. RT-PCR. Total RNA extraction yielded good purity and quantity values. In addition, the integrity of intact RNA was higher (data not shown), and the total RNA samples were found to be free from genomic DNA contamination after treatment with RNase-free DNase I and gDNA wipeout buffer. High concentrations of cDNA were obtained, and the RTPCR amplicons showed positive expression signals for each of determinant genes in different spa type clones (Figure 4 and Table 3). Quantified RT-PCR amplicon intensities of selected genes using Nanodrop spectrophotometer were illustrated in Table 4.

\section{Discussion}

The attachment of microbial cells to surfaces and accumulation of these cells in forming multilayered cell clusters are key steps in an infection [20]. In this regard, adhesion formation is considered as one of the major virulence factors in $S$. aureus. Providing the phenotypic characterization of adhesion/slime formation and genotypic characterization of MSCRAMM/biofilm genes of different clones of $S$. aureus isolates may allow a better understanding of the complex process of infections caused by biofilms. In this study, modified Congo red agar and microtiter tissue culture plates 


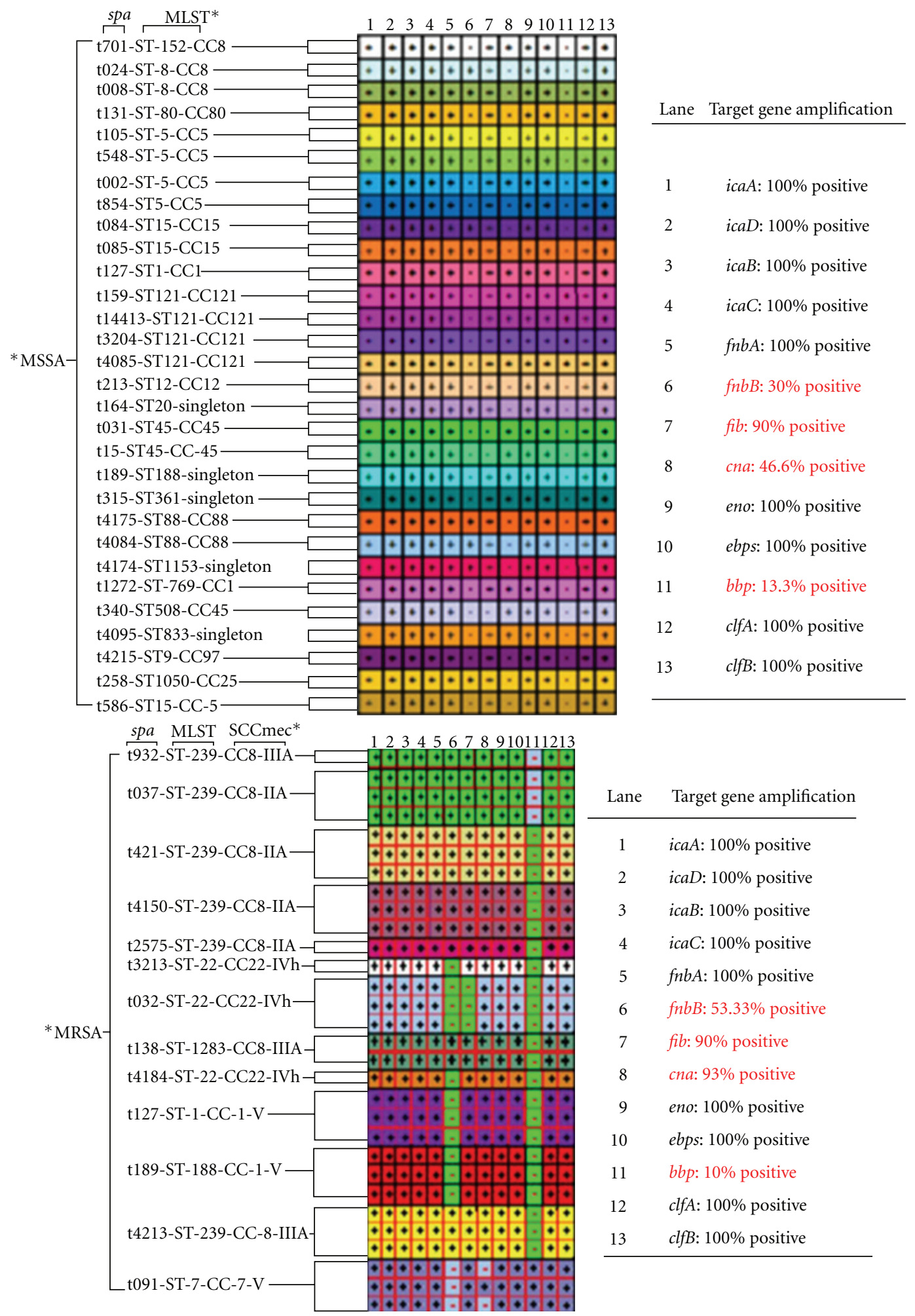

FIgURE 2: Comparing the differences in the molecular determination of the microbial surface components recognizing adhesive matrix molecules (MSCRAMMs) and biofilm genes between MSSA and MRSA isolates. $b b p$ : sialoprotein binding protein, fnbB: fibronectin binding protein $\mathrm{B}$, and cna: collagen binding protein. The intercellular adhesion biofilm genes: $i c a A D B C$, fibronectin binding protein $\mathrm{A}$ (fnbA), laminin binding protein (eno), elastin binding protein (ebpS), and clumping factors A and B (clfA and B), their distribution did not differ between clones associated with MSSA and those with MRSA. Spa refers to Staphylococcal surface protein A. MLST* refers to multilocus sequence typing. SCCmec* refers to staphylococcal cassette chromosome. MSSA* refers to methicillin-senstive Staphylococcus aureus. MRSA* refers to methicillin-resistant Staphylococcus aureus. 
TABLE 4: Comparison of gene expression levels among 6 different clones of spa types by measuring the band intensities of RT-PCR amplicons using nanodrop spectrophotometer $(\mathrm{ng} / \mu \mathrm{L})$.

\begin{tabular}{|c|c|c|c|c|c|c|}
\hline gene & $\begin{array}{c}{ }^{\mathrm{a}} \mathrm{MLST} \\
\mathrm{ST}-121 \\
\text { spa-t3204 }\end{array}$ & $\begin{array}{c}{ }^{\mathrm{a}} \mathrm{MLST} \\
\text { ST-121 } \\
\text { spa-t14413 }\end{array}$ & $\begin{array}{c}{ }^{\mathrm{a}} \mathrm{MLST} \\
\text { ST-121 } \\
\text { spa-t159 }\end{array}$ & $\begin{array}{c}{ }^{\mathrm{b}} \text { MLST } \\
\text { ST-239 } \\
\text { spa-t4150 }\end{array}$ & $\begin{array}{c}{ }^{\mathrm{b}} \text { MLST } \\
\text { ST-239 } \\
\text { spa-t421 }\end{array}$ & $\begin{array}{c}{ }^{\mathrm{b}} \text { MLST } \\
\text { ST-239 } \\
\text { spa-t037 }\end{array}$ \\
\hline$i c a A$ & $598.11 \pm 1.06$ & $698.19 \pm 3.21$ & $815.04 \pm 3.1$ & $796.19 \pm 1.01$ & $716.05 \pm 0.74$ & $515.06 \pm 0.59$ \\
\hline$i c a D$ & $577.87 \pm 12.14$ & $675.76 \pm 2.01$ & $991.55 \pm 1.1$ & $875.88 \pm 0.8$ & $892.41 \pm 2.33$ & $691.37 \pm 0.78$ \\
\hline$i c a B$ & $708.88 \pm 2.04$ & $803.77 \pm 2.31$ & $764.13 \pm 0.8$ & $601.87 \pm 0.45$ & $865.52 \pm 1.02$ & $864.48 \pm 2.86$ \\
\hline$i c a C$ & $591.95 \pm 1.8$ & $699.88 \pm 3.02$ & $600.64 \pm 12.1$ & $998.94 \pm 0.66$ & $9001.65 \pm 1.52$ & $567.59 \pm 3.22$ \\
\hline$f n b A$ & $684.56 \pm 5.7$ & $785.49 \pm 1.33$ & $904.95 \pm 14.1$ & $488.55 \pm 2.41$ & $805.86 \pm 1.10$ & $504.71 \pm 1.81$ \\
\hline$f n b B^{c}$ & & & & $749.72 \pm 2.11$ & $909.17 \pm 4.2$ & $800.84 \pm 1.23$ \\
\hline Fib & $544.35 \pm 21.01$ & $643.72 \pm 9.02$ & $783.13 \pm 1.9$ & $949.37 \pm 3.01$ & $681.78 \pm 3.11$ & $483.42 \pm 12.1$ \\
\hline cna & $560.85 \pm 14.1$ & $661.93 \pm 1.60$ & $660.35 \pm 0.6$ & $360.84 \pm 0.8$ & $559.89 \pm 2.81$ & $360.81 \pm 9.22$ \\
\hline eno & $461.06 \pm 5.1$ & $565.15 \pm 11.5$ & $558.28 \pm 0.4$ & $464.05 \pm 0.77$ & $454.92 \pm 0.62$ & $458.94 \pm 0.96$ \\
\hline$e b p s$ & $542.18 \pm 1.3$ & $641.28 \pm 2.12$ & $506.78 \pm 0.88$ & $543.17 \pm 9.1$ & $405.14 \pm 0.73$ & $806.37 \pm 0.89$ \\
\hline$b b p^{\mathrm{d}}$ & $580.52 \pm 2.4$ & $684.39 \pm 2.11$ & $474.13 \pm 2.03$ & & & \\
\hline clfA & $955.26 \pm 11.8$ & $1051.49 \pm 1.01$ & $466.45 \pm 2.01$ & $552.29 \pm 0.33$ & $765.54 \pm 2.39$ & $766.68 \pm 0.99$ \\
\hline $\operatorname{clfB}$ & $759.44 \pm 2.1$ & $859.67 \pm 2.10$ & $459.50 \pm 1.04$ & $755.41 \pm 2.62$ & $556.67 \pm 0.59$ & $659.81 \pm 1.78$ \\
\hline
\end{tabular}

${ }^{a}$ Three clones of MLST sequence type ST121 belonging to clonal cluster 121 (CC121) with different spa types were showed to be weakly adherent to the surface of polystyrene microtiter plat after $48 \mathrm{~h}$ growth, these clones were found positive for 12 genes except the $f n b B$ gene ${ }^{c}$. ${ }^{b}$ Three clones of MLST sequence type ST239 belonging to clonal cluster 8 (CC8) with different spa types were showed to be strongly adherent to the surface of polystyrene microtiter plat after $48 \mathrm{~h}$ growth, these clones were found positive for 12 genes except the $b b p$ gene $^{\mathrm{d}}$. Every six different clones showed statistically significant difference $(P \leq 0.05)$ in the intensity of RT-PCR amplified products when fewer cycles were used (25) in the linear phase of amplification for most transcripts. The replicates of Rt-PCR products were done in duplicate.

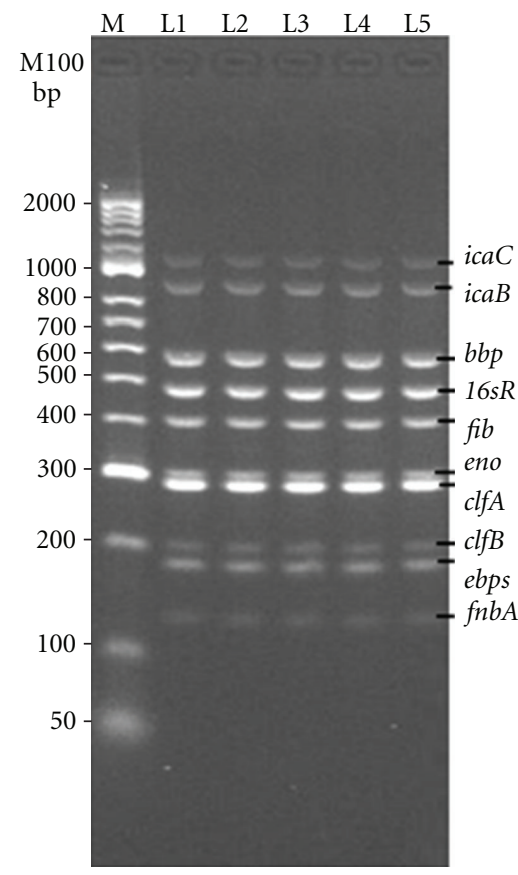

(a)

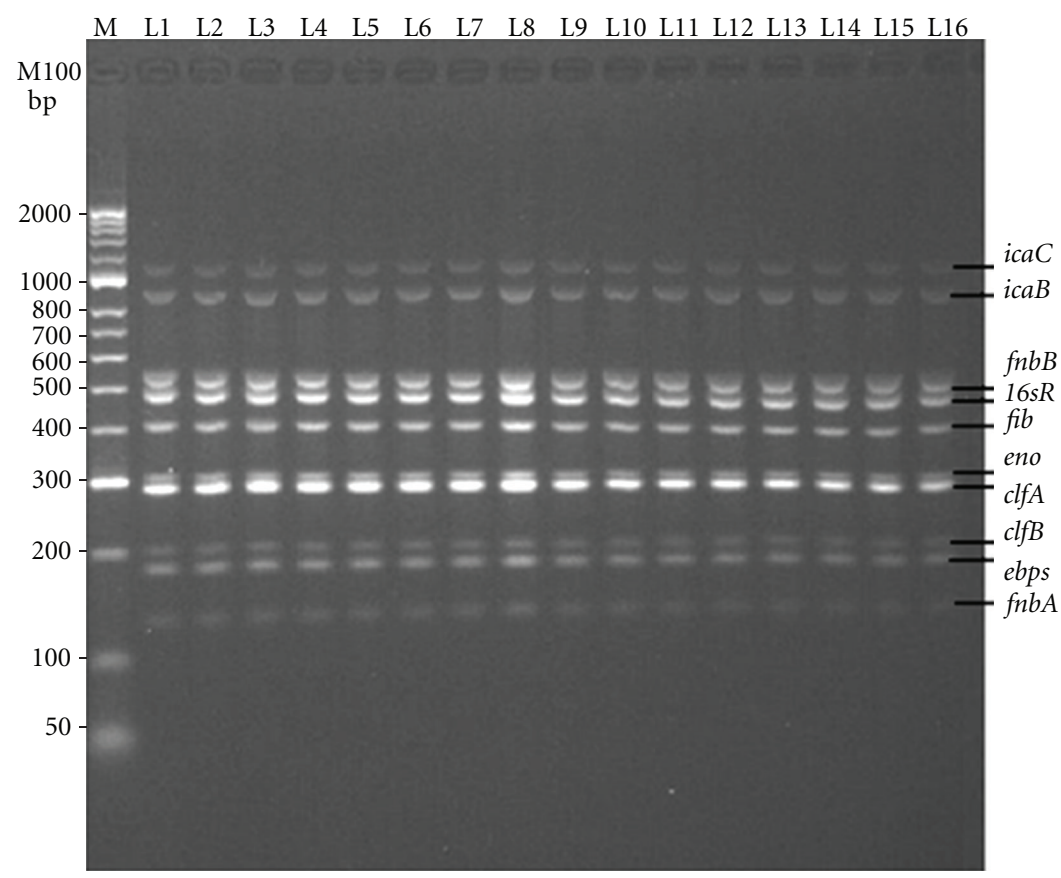

(b)

Figure 3: ( $a, b)$ Multiplex PCR amplification of MSCRAMMs and biofilm genes of MRSA and MSSA clinical isolates. (a) is related to the amplified bands of 10 genes of icaA, icaD, icaB, icaC, bbp, fib, eno, clfA, clfB, ebbps, and finbA at 1100, 900, 574, 404, 301, 288, 203, 180 , and $128 \mathrm{bp}$, respectively, in one tube reaction, all these genes were determined in 5 different clones of MRSA and MSSA: MRSA-spat091(L1), MSSA-spa-t159(L2), MSSA-spa-t14413(L3), MSSA-spa t3204(L4), MSSA-spa-t4085(L5). (b) is related to all the 10 amplified genes mentioned in (a) except $b b p$, which was replaced with finbB at $523 \mathrm{bp}$ and was found in 16 different clones of MRSA: MRSA-spa-t932(L1), t037(L2, L3, L4), t421(L5, L6, L7), t41509(L8, L9, L10), t2575(L11), t138(L12, L13), and t4213(L14, L15, L16). 16sRNA at product size $455 \mathrm{bp}$ was used as internal positive control. $\mathrm{M}$ is DNA ladder marker. 


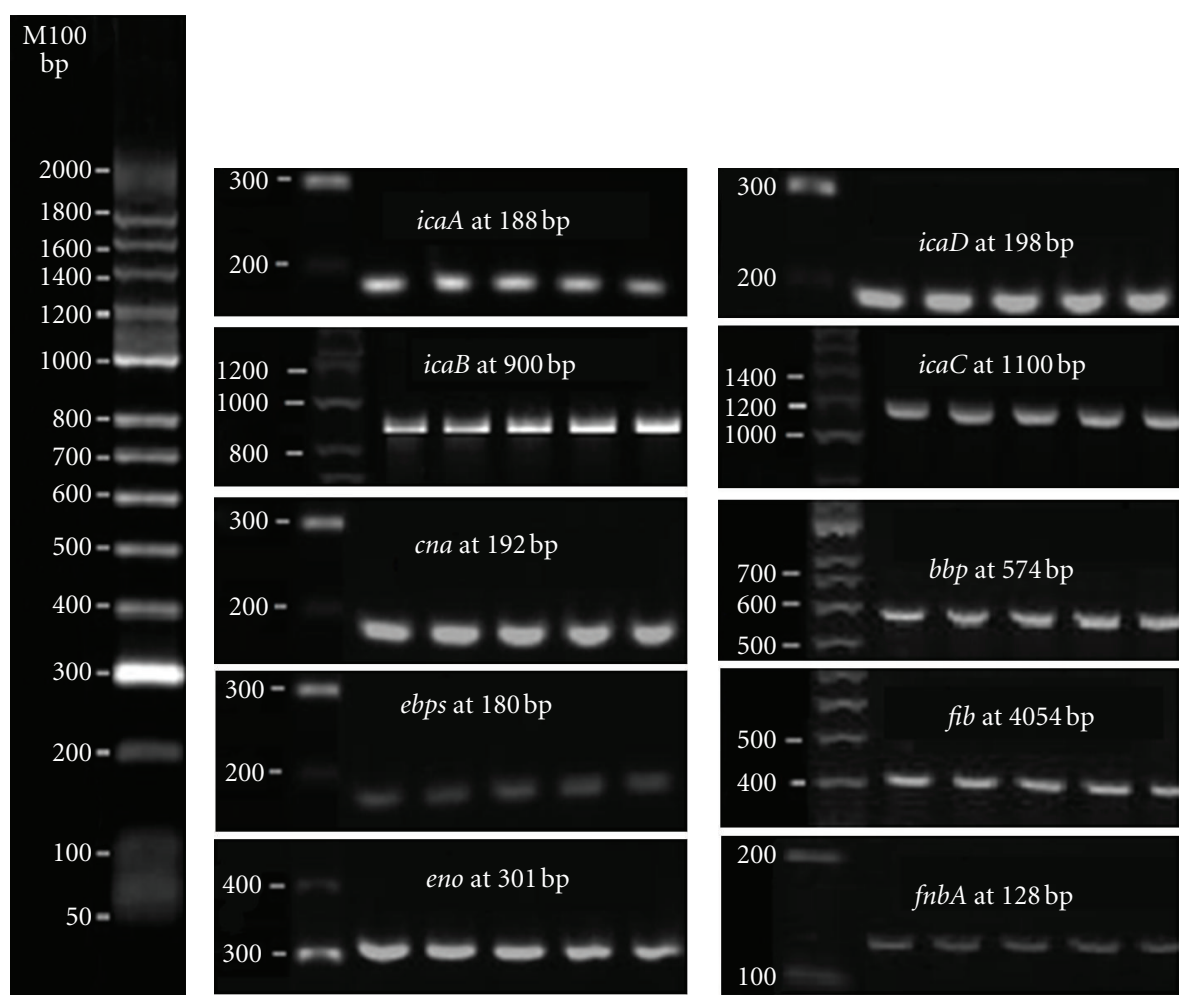

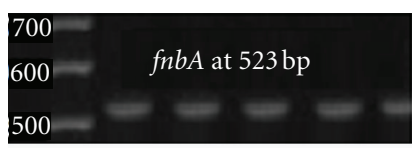
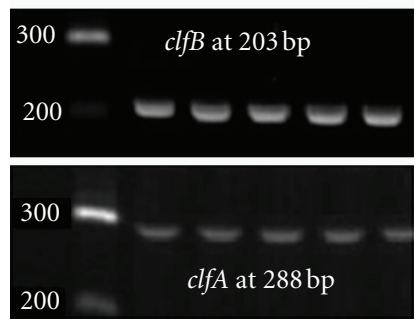

FIGURE 4: Products of RT-PCR performed on RNA isolated from MSSA and MRSA clones. The presence of RT-PCR products indicates expression of 13 adhesion and biofilm genes. All the genes in this figure were prepared by cutting and pasting from original amplified products in the gel for each gene determined in this study. M100 is DNA base pair size marker.

were chosen to detect slime production as well as to quantify the adherence since biofilm formation should be confirmed by genotypic characterization methods [21]. Table 2 shows a variable slime- and adherence-forming capacities of 60 different clones of MSSA and MRSA isolates tested, some clones belonging to the same spa type were found to be strongly adherent to polystyrene microtiter plates surface but showed variable slime production on Congo red agar. However, some clones of different spa types were found to be negative for slime production but strongly adherent to the surface of polystyrene microtiter plates. All clones of MSSA and MRSA isolates tested were found to be positive for $i c a A D B C$ genes (Figure 2) and gene expression studies by RTPCR confirmed that all isolates were positive for expression (Table 3). Thus, the variation between phenotypic and genotypic characterization may be due to the heterogeneity in the genetic origins, and not because of the presence or absence of genes required for the biofilm. Our findings were similar to the observations by Arciola et al. [14] as there was no difference in the distribution of icaA and icaD genes in strains of high and low virulence of $S$. aureus and the variation has been shown in the phenotypic characterization. The prevalence of clfB, clfA, ebps, eno, fnbA, and fib in the tested clones was comparable with that found in MSSA and MRSA. The prevalence of $c n a$ and $f n b B$, however, was much higher in the MRSA than in the MSSA clones, (93\% versus $46.6 \%$ and $53.3 \%$ versus $30 \%$, resp.) However, a prevalence of $b b p$ found in MRSA and MSSA was comparable but with the low percentage in MSSA and MRSA clones, $13.3 \%$ and $10 \%$ respectively as shown in Figure 2. According to Seo et al. [2], the variation in the prevalence of MSCRAMM genes depends on the species of Staphylococcus isolates, and similar observations were obtained in this study. The distribution of MSCRAMM genes among different clones of MSSA and MRSA clinical isolates was as follows: 21 clones were positive for 8 of 9 MSCRAMM genes, 26 were positive for 7 genes, and 13 were positive for 6 genes. Of all the 60 clones tested, all clones harbored at least 5 MSCRAMM genes whereas $b b p$ was not found in 53 clones. Vancraeynest et al. [22] also reported similar results indicating that the majority of the $S$. aureus carries MSCRAMMs genes. In addition, RTPCR amplicons showed positive bands for each determinant gene prevalent in different spa clones (Figure 4 and Table 3). Although, significant differences in gene expression may not be detectable with the bands, it is possible to compare the differences in the expression of the selected genes in the linear phase of amplification by measuring band intensities of the RT-PCR products [18]. The number of expressing genes should be highly correlated with the formation of biofilm adhesion, but in this study the MSCRAMMs and icaADBC genes were expressed at varying different quantities (levels) in 6 clones (Table 4). Some MSCRAMMs and icaADBC gene expression levels were higher except in weakly adherent clones, instead found at lower levels in strongly adherent clones. Unexpectedly, the expression levels of selected genes in weakly adherent clones were found to be higher than in 
the strongly adherent clones. We suggest that the expression of MSCRAMM and biofilm genes depends on the type of clones and not based on the strong or weak adhering properties of the clones. This is in full compliance with the diversity occurring with phenotypic characteristics on MCRA and MTCP as mentioned earlier. There was no correlation in distribution of MSCRAMM and biofilm genes with morphology, which indicates that a single gene or subset of genes cannot be utilized as a biofilm indicator for morphology unless additional studies are warranted to understand the correlation between biofilm formation and bacterial adhesion. In summary, it has been shown that $S$. aureus clones have different capacities to form slime and adherence. This may be caused by a difference in the spa types of MRSA and MSSA clones and not due to their differences in the expression of MSCRAMM genes. Differences occurring due to clonal variation indicate a need for accurate clonal identification for the effective biofilm management upon infection.

\section{Acknowledgments}

The authors take this opportunity to thank the Department of Medical Microbiology and Parasitology, Universiti Putra Malaysia for kindly providing all of the MRSA isolates. Financial support by the Ministry of Science, Technology and Innovation Malaysia (MOSTI) Science Fund with Grant no. 5524112 is gratefully acknowledged.

\section{References}

[1] J. W. Costerton, P. S. Stewart, and E. P. Greenberg, "Bacterial biofilms: a common cause of persistent infections," Science, vol. 284, no. 5418, pp. 1318-1322, 1999.

[2] Y. S. Seo, D. Y. Lee, N. Rayamahji, M. L. Kang, and H. S. Yoo, "Biofilm-forming associated genotypic and phenotypic characteristics of Staphylococcus spp. Isolated from animals and air," Research in Veterinary Science, vol. 85, no. 3, pp. 433438, 2008.

[3] K. Chaieb, K. Mahdouani, and A. Bakhrouf, "Detection of icaA and icaD loci by polymerase chain reaction and biofilm formation by Staphylococcus epidermidis isolated from dialysate and needles in a dialysis unit," Journal of Hospital Infection, vol. 61, no. 3, pp. 225-230, 2005.

[4] C. Cucarella, C. Solano, J. Valle, B. Amorena, I. Lasa, and J. R. Penades, "Bap, a Staphylococcus aureus surface protein involved in biofilm formation," Journal of Bacteriology, vol. 183, no. 9, pp. 2888-2896, 2001.

[5] C. Cucarella, M. A. Tormo, E. Knecht et al., "Expression of the biofilm-associated protein interferes with host protein receptors of Staphylococcus aureus and alters the infective process," Infection and Immunity, vol. 70, no. 6, pp. 3180-3186, 2002.

[6] H. Rohde, J. K. M. Knobloch, M. A. Horstkotte et al., "Correlation of Staphylococcus aureus icaADBC genotype and biofilm expression phenotype," Journal of Clinical Microbiology, vol. 39, no. 12, pp. 4595-4596, 2001.

[7] S. Kiem, W. S. Oh, K. R. Peck et al., "Phase variation of biofilm formation in Staphylococcus aureus by IS256 insertion and its impact on the capacity adhering to polyurethane surface," Journal of Korean Medical Science, vol. 19, no. 6, pp. 779-782, 2004.
[8] A. Tristan, L. Ying, M. Bes, J. Etienne, F. Vandenesch, and G. Lina, "Use of multiplex PCR to identify Staphylococcus aureus adhesins involved in human hematogenous infections," Journal of Clinical Microbiology, vol. 41, no. 9, pp. 4465-4467, 2003.

[9] D. Vancraeynest, K. Hermans, and F. Haesebrouck, "Genotypic and phenotypic screening of high and low virulence Staphylococcus aureus isolates from rabbits for biofilm formation and MSCRAMMs," Veterinary Microbiology, vol. 103, no. 3-4, pp. 241-247, 2004.

[10] L. Montanaro, C. Renata Arciola, L. Baldassarri, and E. Borsetti, "Presence and expression of collagen adhesin gene (cna) and slime production in Staphylococcus aureus strains from orthopaedic prosthesis infections," Biomaterials, vol. 20, no. 20, pp. 1945-1949, 1999.

[11] E. Ghaznavi-Rad, M. N. Shamsudin, Z. Sekawi et al., "Predominance and emergence of clones of hospital-acquired methicillin-resistant Staphylococcus aureus in Malaysia," Journal of Clinical Microbiology, vol. 48, no. 3, pp. 867-872, 2010.

[12] H. Ghasemzadeh-Moghaddam, E. Ghaznavi-Rad, Z. Sekawi et al., "Methicillin-susceptible Staphylococcus aureus from clinical and community sources are genetically diverse," International Journal of Medical Microbiology, vol. 7, pp. 505-549, 2010.

[13] J. A. Wu, C. Kusuma, J. J. Mond, and J. F. Kokai-Kun, "Lysostaphin disrupts Staphylococcus aureus and Staphylococcus epidermidis biofilms on artificial surfaces," Antimicrobial Agents and Chemotherapy, vol. 47, no. 11, pp. 3407-3414, 2003.

[14] C. R. Arciola, L. Baldassarri, and L. Montanaro, "Presence of ica $\mathrm{A}$ and ica $\mathrm{D}$ genes and slime production in a collection of Staphylococcal strains from catheter-associated infections," Journal of Clinical Microbiology, vol. 39, no. 6, pp. 2151-2156, 2001.

[15] N. S. Mariana, S. A. Salman, V. Neela, and S. Zamberi, "Evaluation of modified Congo red agar for detection of biofilm produced by clinical isolates of methicillin resistance Staphylococcus aureus," African Journal of Microbiology Research, vol. 3, pp. 330-338, 2009.

[16] C. R. Arciola, D. Campoccia, L. Baldassarri et al., "Detection of biofilm formation in Staphylococcus epidermidis from implant infections. Comparison of a PCR-method that recognizes the presence of ica genes with two classic phenotypic methods," Journal of Biomedical Materials Research A, vol. 76, no. 2, pp. 425-430, 2006.

[17] S. Stepanović, D. Vuković, V. Hola et al., "Quantification of biofilm in microtiter plates: overview of testing conditions and practical recommendations for assessment of biofilm production by staphylococci," Acta Pathologica Microbiologica Scandinavica, vol. 115, no. 8, pp. 891-899, 2007.

[18] M. J. Guimaraes, L. Frank, Z. Albert, and M. Terrill, “Differential display by PCR: novel findings and applications," Nucleic Acids Research, vol. 23, no. 10, pp. 1832-1833, 1995.

[19] S. S. Atshan, N. S. Mariana, T. T. L. Leslie et al., "Improved method for the isolation of RNA from bacteria refractory to disruption, including S. aureus producing biofilm," Gene, vol. 494, pp. 219-224, 2011.

[20] P. Vaudaux, H. Yasuda, M. I. Velazco et al., "Role of host and bacterial factors in modulating staphylococcal adhesion to implanted polymer surfaces," Journal of Biomaterials Applications, vol. 5, no. 2, pp. 134-153, 1990.

[21] P. Vasudevan, M. K. M. Nair, T. Annamalai, and K. S. Venkitanarayanan, "Phenotypic and genotypic characterization of bovine mastitis isolates of Staphylococcus aureus for biofilm 
formation," Veterinary Microbiology, vol. 92, no. 1-2, pp. 179185, 2003.

[22] D. Vancraeynest, K. Hermans, and F. Haesebrouck, "Genotypic and phenotypic screening of high and low virulence Staphylococcus aureus isolates from rabbits for biofilm formation and MSCRAMMs," Veterinary Microbiology, vol. 103, no. 3-4, pp. 241-247, 2004. 

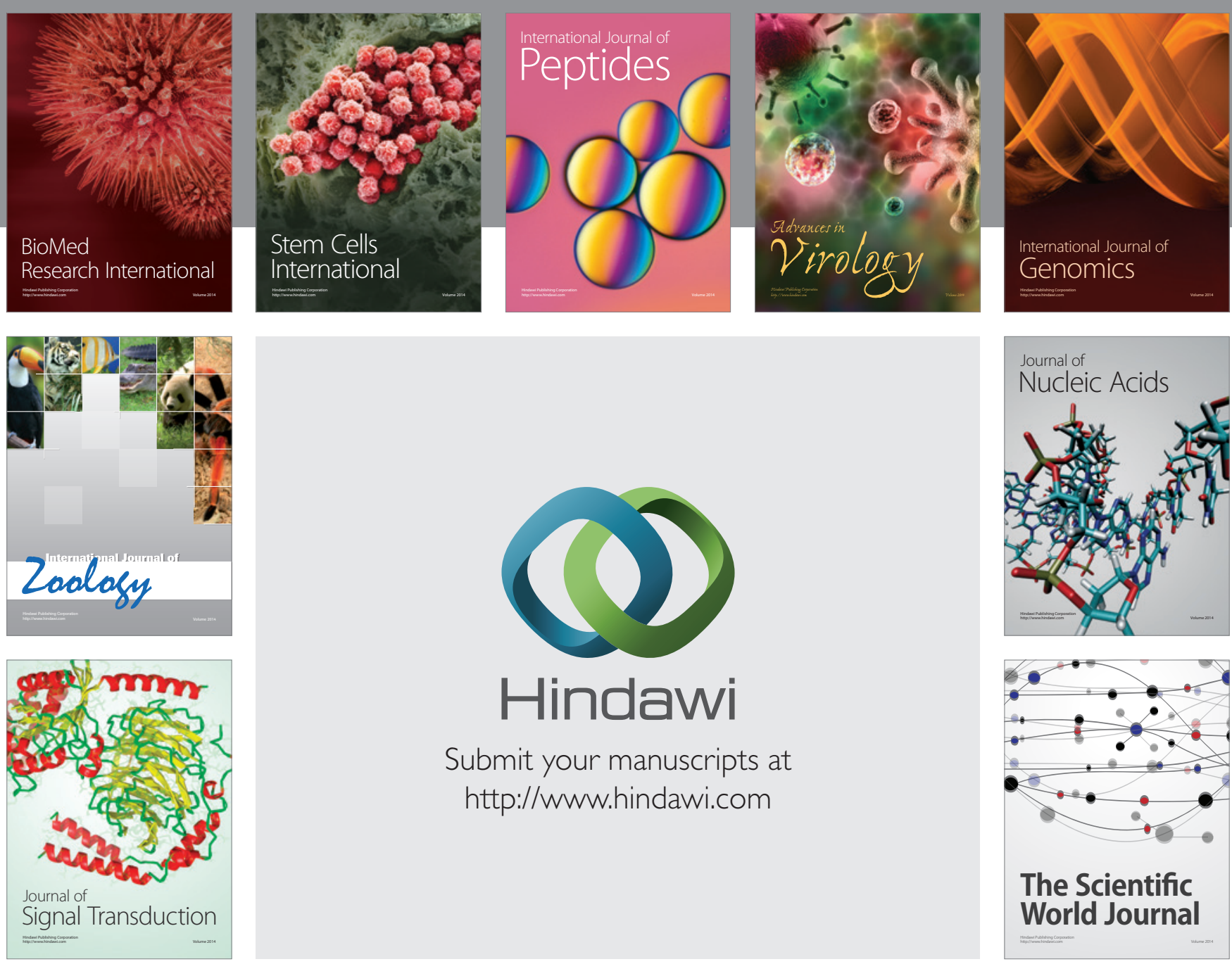

Submit your manuscripts at

http://www.hindawi.com
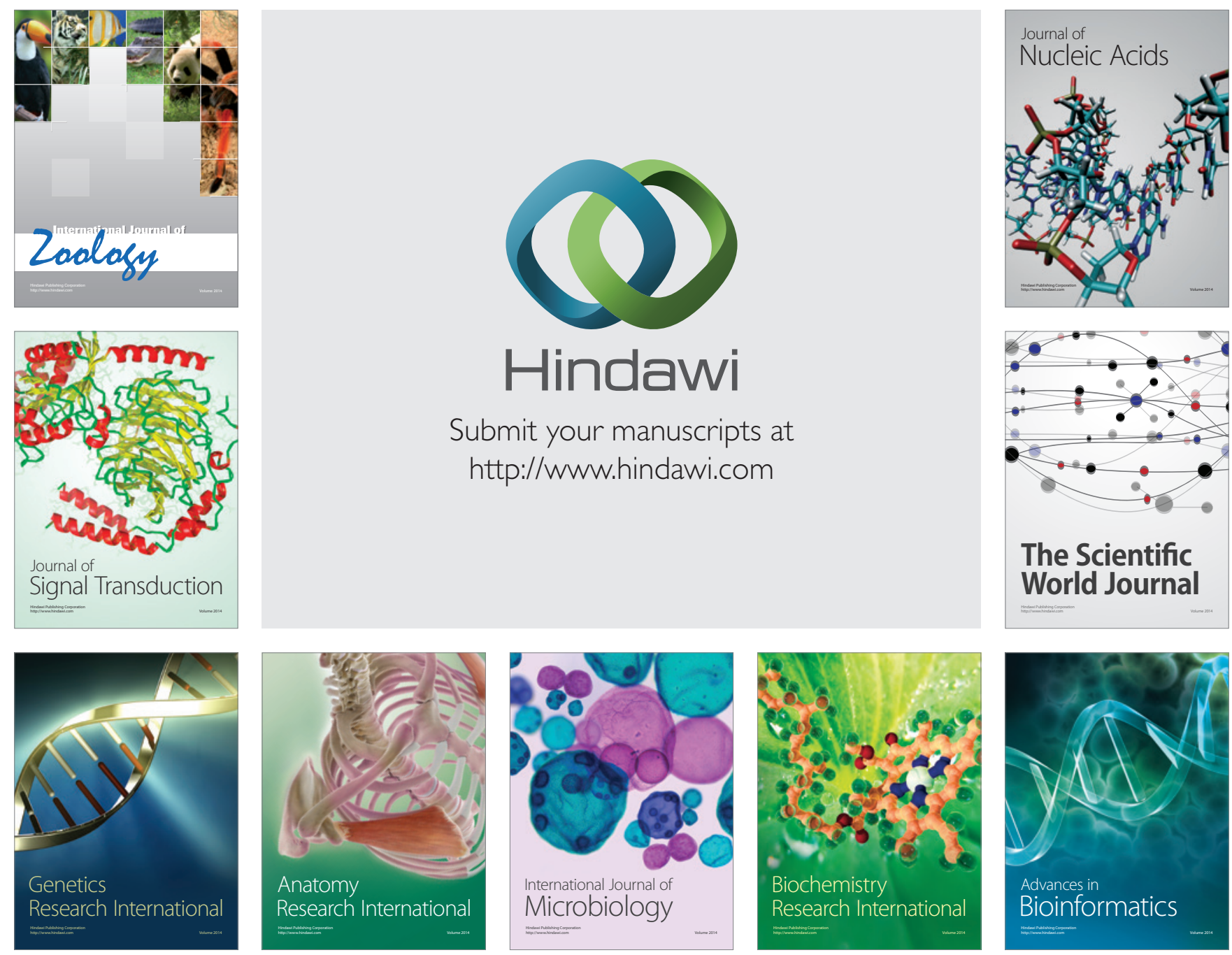

The Scientific World Journal
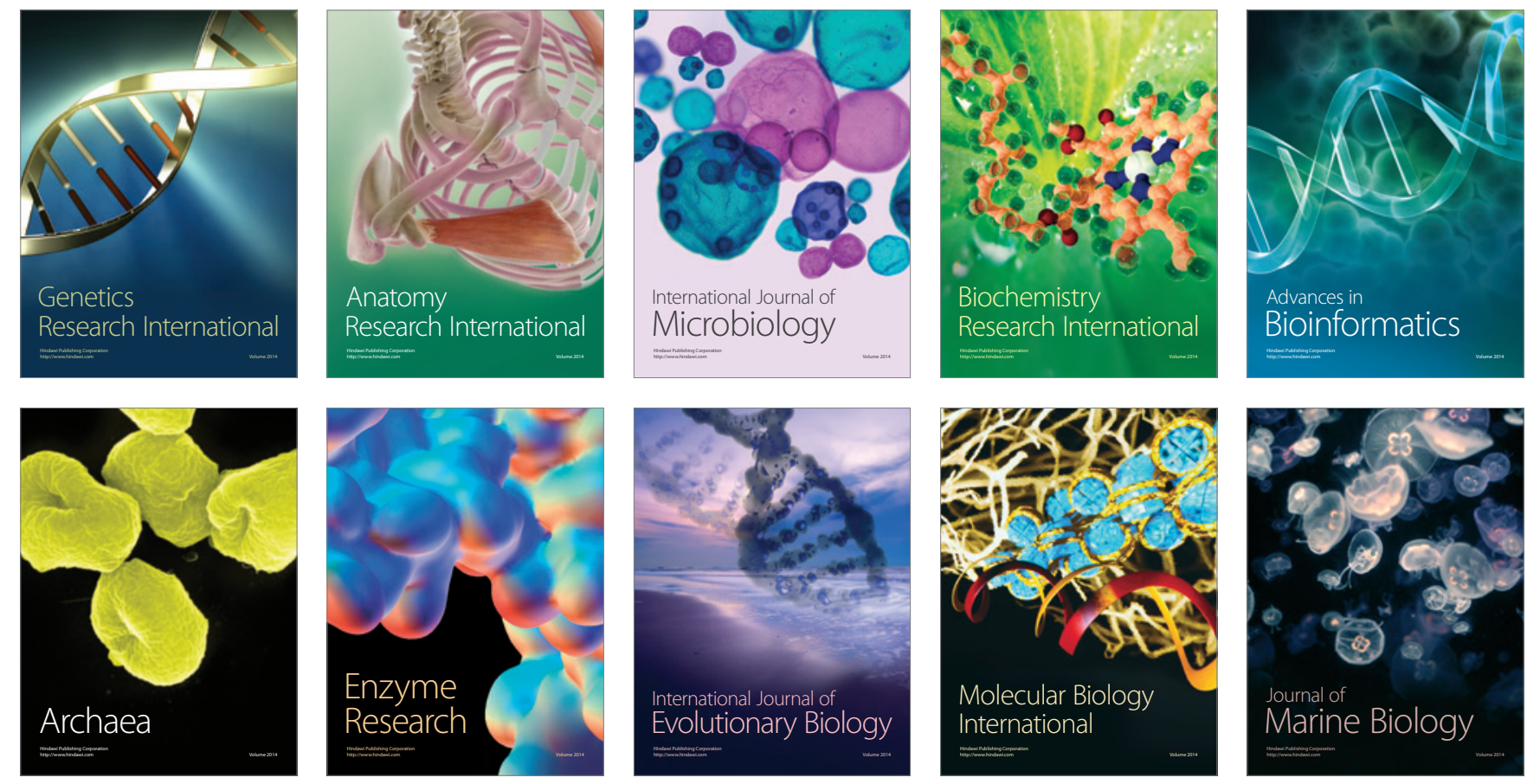